\title{
Crosstalk of brassinosteroids with other phytohormones under various abiotic stresses
}

\author{
Farhan Ahmad ${ }^{1}$, Ananya Singh², Aisha Kamal ${ }^{*}$ \\ ${ }^{1}$ Department of Bioengineering, Integral University, Lucknow, Uttar Pradesh, India, ${ }^{2}$ Department of Biosciences, Integral University, Lucknow, Uttar Pradesh, India
}

\begin{tabular}{|c|c|}
\hline $\begin{array}{l}\text { Article history: } \\
\text { Received on: September } 02,2017 \\
\text { Accepted on: October } 24,2017 \\
\text { Available online: January } 17,2018\end{array}$ & $\begin{array}{l}\text { Brassinosteroids (BRs) are the most important growth hormones which are steroidal in nature play crucially involved } \\
\text { in growth and progressions of the plant. In recent years, advancements done in accessibility of biological possessions } \\
\text { and approaches led to the most applicable mechanisms involved in BRs de novo synthesis, translocation and signaling } \\
\text { pathways. The current researchers are also associated with the flexible roles of BRs. From the previous studies, it was }\end{array}$ \\
\hline $\begin{array}{l}\text { Key words: } \\
\text { Plant hormone } \\
\text { Brassinosteroids } \\
\text { Abiotic stress } \\
\text { Antioxidant }\end{array}$ & $\begin{array}{l}\text { manifest that BRs interaction with salicylic acid, abscisic acid, auxin, gibberellin, ethylene, cytokinin, and jasmonic } \\
\text { acid in controlling numerous morphophysiological processes in plants. In this section, an effort is made to understand } \\
\text { mysterious development and growth-linked either directly or not directly to BRs signaling and its intra- and inter- } \\
\text { relations with various phytohormones. This, in sequence, will support emerging extrapolative representations to } \\
\text { moderate various valuable qualities in plants and address current encounters in agriculture. }\end{array}$ \\
\hline
\end{tabular}

\section{INTRODUCTION}

Stresses, either abiotic or biotic, seriously influence agricultural profitability and world farming is confronting the test of expanding the efficiency keeping in mind the end goal to pace up with the expanding nourishment request of the developing populace [1]. These stresses incorporate various factors such as of light, ultraviolet radiations, temperature (high and low), drought, flood, submergence, heavy metal stress, $\mathrm{pH}$ alteration, salinity increments, nutrient imbalance, gaseous pollutants (ozone, sulfur dioxide), and many other less commonly occurring stress. Furthermore, overproduction of reactive oxygen species (ROS) also enhanced abiotic stress inducing critical damages to the primary metabolites, destructions of biochemical components such as of proteins, lipids, carbohydrates, and interferes with the molecular process that ultimately halts cellular metabolism. Thus, abiotic stresses altered almost all metabolic process of the plant from the beginning period of seed germination to development till maturity. The changes marked in various stages of the plant growth and ultimately reduced the overall yields of plants. Further assist it has been assessed that abiotic stresses may negatively impact $70 \%$ yield of staple support crops $[2,3]$. Furthermore, expanding salinization of arable land is relied on to bring about $30 \%$ land-misfortunes before 2028 and half by mid of the $21^{\text {st }}$ century [4]. Plant development controllers assume imperative parts

*Corresponding Author

Aisha Kamal

Department of Bioengineering,

Integral University, Dasauli, Kursi Road,

Lucknow - 226 026, Uttar Pradesh, India.

E-mail: aishakama104@gmail.com in the direction of plant development process and signaling systems, either specifically or by implication in an extensive variety of biotic and abiotic stress $[5,6]$.

In this context, brassinosteroids (BRs), an important steroidal plant regulator involved directly or indirectly in enhancing plant growth and development process by regulating various mechanisms. BRs not only trigger the germination, cell division, cell elongation, root growth development, induction ethylene biosynthesis [7] but also regulate cell cycle [8]. Moreover, BRs stimulate the growth of apical meristems in potato tubers [9], speeding up of the frequency of cell division in Petunia hybrida [10] and cell division and leaf expansion [11]. BRs also (directly or indirectly) involved in germination process, enhancing photosynthesis, regulating senescence also in the vegetative process as well as defensive and mitigating responses to different abiotic and stress [12]. Remarkably, BRs may be applied to plants at germinative, vegetative as well as flowering stage of plants [13] as foliar spray, seed treatment, root application, and also by shotgun approach [14-18]. Not only this, interaction of BRs with other phytohormone facilitates growth and metabolism of plants. Hence, BRs make plant life easier not only by alleviating stresses but also by regulating various physiological parameters.

\subsection{BRs: An Overview}

BRs belong to the class of polyhydroxylated plant steroid hormones reassemble with animal steroid hormones and well-known for regulating various physiological functions such as developmental process involved in embryogenesis, seed and microspore germination, regulation of cell division and differentiation, development and growth of thecae and pollen tubes, and initiates 
flowering and regulated leaf senescence [19]. Many studies have already conducted to understand BRs biosynthesis, structure, degradation, signaling and involvement of BRs in various physiological and developmental processes [20-22]. Endogenous regulation of $\mathrm{BR}$ is critical for various biological functions in plants [23]. The biosynthesis, translocation and metabolism of BR are vital modules of metabolic equilibrium actively maintained endogenous level of BR in plants. Furthermore, BRs act as a master regulator in plant disease resistance, defensive responses to pathogen attack but mechanism related these responses is still less clear and even contentious and needs extensive research [24-27].

\subsection{Historical Background, Chemical Structure, and Biosynthesis}

Over a 30-year period of time, Mitchell and his coworkers while working on various plant, found that extract from pollen of Brassica napus has growth promoting activity and isolated new compound brassins and had a prominent effect on cell division and elongation in the bean second internode bioassay and also increased yields when applied on youngest seedlings of various plants. Based on this initial finding [28] predicts hormonal nature of brassins due to their particular translocatable organic substances extracted from one plant and actuated growth when given in ample amount to another plant. However, interpretation of the main constituent of brassins was fatty acid ester was not correct. The accurate and factual chemical structure and the main constituent of brassin were come into existence after extensive and laborious effort by USDA workers and consumption of huge amount of bee-collected pollen followed by solvent extraction and extensive column chromatography [29]. By X-ray crystallography technique, pure substance was identified as steroidal lactone named brassinolide (BL) [30]. A stereoisomer of BL, 24-epiBL synthesized was chemical to overcome the costly extraction process and production at large scales [31]. Most important advancement was made that positioned the groundwork for elaborating the biosynthetic pathway, endogenous level of BRs, mode of action, recognition of the BR receptor and other coreceptor involved [32]. Nowadays, cost-effective endogenous levels of hormones in plant were detected using by ELISA method [33-35].

BRs structure can be framed as C27 and C28 with alkyl functional group of the side chains. A transfused A/B ring framework containing 2-OH at the position of ring $\mathrm{A}$ and 6-ketone group on the position at ring $\mathrm{B}$ is required for biochemically functional BRs [36]. The chemical alignment (22R, 23R, and 24S) for the most distinguished BR up to this point is shown in Figure 1. In addition, BRs contrast from BL inside the boxed territory (an) and (b) on the premise of a $5 \alpha$-cholestane skeleton [37].

Exhaustive stereochemistry studies illuminated whole paths of the transformation of campesterol to BL through teasterone, typhasterol, and castasterone [39]. Steroidal plants are consolidated by the isoprenoid biosynthetic pathway by means of acetyl-CoA, mevalonate, isopentenyl pyrophosphate, geranyl pyrophosphate, and farnesyl pyrophosphate [Figure 2]. Squalene is incorporated by an abbreviated version of two farnesyl pyrophosphate particles, which is then changed over by means of squalene-2,3-epoxide to cycloartenol. The transformation of squalene-2,3-epoxide to cycloartenol is particular to plants. Cycloartenol is the critical antecedent of plant sterols; current exertion has demonstrated that Arabidopsis contains a useful lanosterol synthase and hence a substitute pathway to plant sterols by means of lanosterol [40].

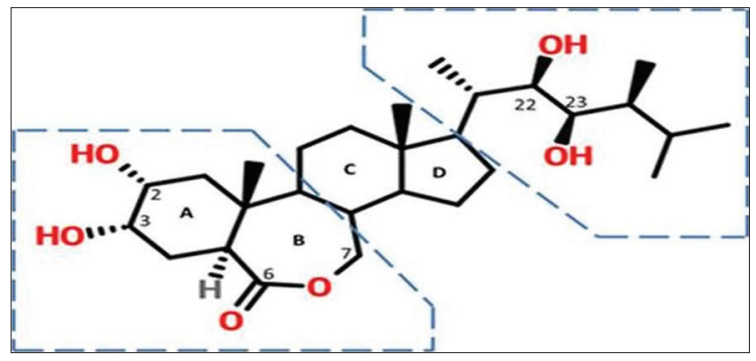

Figure 1: The chemical structure of brassinolide with the steroid rings labeled as $\mathrm{A}, \mathrm{B}, \mathrm{C}$, and $\mathrm{D}[38]$

\section{POSITIVE ROLE OF BRs IN ABIOTIC STRESS}

Wide investigation on improving the function of BRs and related compounds involved in abiotic stresses to plants had been already done. In this section, discussion will consider the possible role of BRs in various stresses, induction of antioxidant system, mode of action and also crosstalk of BRs with other stress mitigating molecules, phytohormone, and various signaling pathways involved.

\subsection{Temperature Stress}

In the present environmental scenario, both chilling stress and high temperature have negative impact on the crop plants. BRs and related composites evoke antioxidant defense system and ultimately improve plant growth and metabolism in different plants exposed to both high [41] and low temperature [42]. Plant exposed to chilling stress BR reduce the ion outflow [43], whereas, 24-epiBL felicitate enzymatic activity (antioxidant) in grapevines exposed to chilled treatment [44]. Under chilling $\left(4^{\circ} \mathrm{C}\right)$ conditions, exogenous application of 24-epiBL eased the lethal effect of $\mathrm{H}_{2} \mathrm{O}_{2}$ through by activating antioxidant defense system such as CAT, APX, and superoxide dismutase (SOD) in Brassica juncea seed [45]. Furthermore, in cucumber exogenous application of 24-epiBL mitigate chilling-induced reticence of photosynthesis by dropping ROS generation and enhanced activities of SOD, APX. The reduction in chilling injury, ion leakage, membrane integrity, and enhanced osmoprotectant, phenylalanine ammonia-lyase activity due to ameliorative effect of ample concentration of BR (3.0 and $6.0 \mu \mathrm{M}$ ) exogenously applied to tomato plants [42]. Furthermore, the physiological and molecular impact of 24-epiBL on tomato plants are more tolerant to high temperature as compared to an untreated plant.

\subsection{Low Temperature}

Detailed alleviating effects of BRs on the chilling stress presented by different researchers and in various literature. In detailed study, it was observed that EpiBL- treatment to tomato seedlings enhanced tolerance against heat shock (HS) by improving ionic leakage and enhancement defense system [41]. BR also alleviated low irradiances in Oryza sativa by enhancing soluble protein content as well as chlorophyll content. In Arabidopsis, exogenous use of BL was reported to uphold root elongation and lateral root germination [46].

\subsection{Drought Stress}

Drought recognized as the most severe abiotic stresses presently, affecting agriculture by reducing photosynthetic pigments synthesis, stomatal conductance and photosynthesis machinery that lead to declined growth of plants [47]. BL mitigate adverse effects and enhanced salt tolerance in Zea mays by improving soluble proteins 


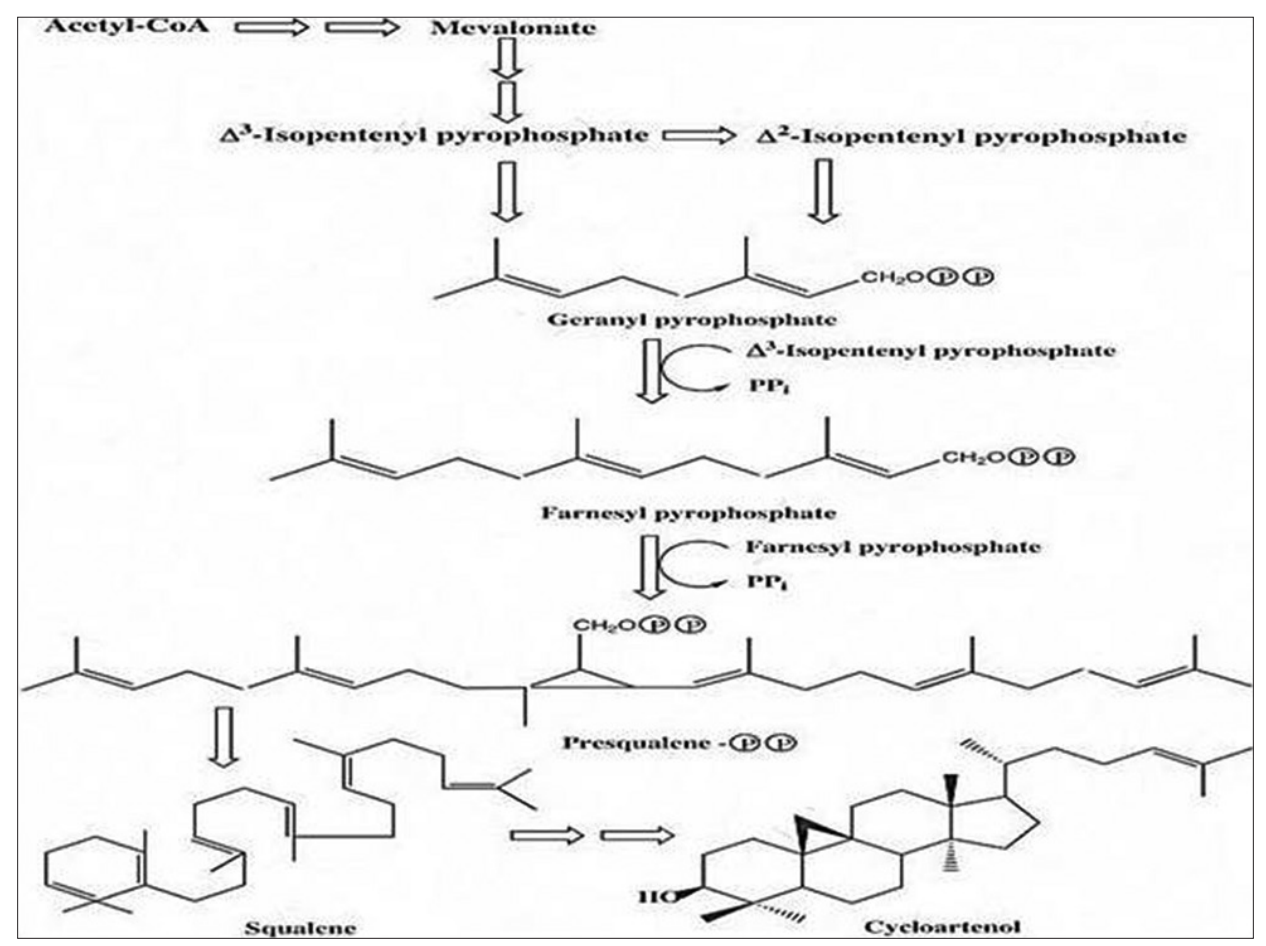

Figure 2: Biosynthetic pathway of the plant sterol precursor, cycloartenol, from mevalonate

content, proline content, and antioxidant activities [48]. BR treatment of seedlings of two varieties of wheat (Sakha 69 -drought-resistant) and (Giza 164-drought-sensitive) grown in drought stress condition showed enhanced high relative leaf content, increased the content of proline, upregulation of water stress-inducible proteins and also de novo synthesis of specific polypeptides [49].

\subsection{Salinity Stress}

Approximately, 45 million hectares of irrigated land reported to be smashed by salinity stress and is increasing day-by-day worldwide $[50,51]$. The negative effects of salinity include toxicity induced by ion accumulation, osmotic stress, nutrient-imbalance and homeostasis/deficiency, amplified cell-turgor loss, reduced leaf water potential, disturbed physiological/biochemical processes, and excessive ROS generation [51]. In Cucumis sativus seedlings, exogenous BL application markedly reduced salinity stress, increased seed viability, and reduced electrolyte leakage by enhancing SOD, POD, and CAT activity. Furthermore, exogenous spraying of 24-epiBL to salinity-exposed Phaseolus vulgaris enriched the MSI, RLWC due to enhanced antioxidative enzymes and proline content [52].

\subsection{Metalloid Stress}

In sustainable agriculture, metal/metalloid stress is a serious concern directly related with environment. Agricultural soils exposed to different metal pollutants from industrial wastes, agricultural wastes, presence of heavy metals, sewage waste disposal, etc., which led to decrease the overall efficiency of plant. Application of BRs to Cd heavy metals of different concentration $(3.0-12 \mathrm{mg} / \mathrm{kg})$ to Solanum lycopersicum plants upgraded cell reinforcement framework (antioxidant system) ultimately enhanced organic product yield and quality [53]. Improved Cd- tolerance in $P$. vulgaris was also reported which may be due to the activity of 24-epiBL $(5 \mu \mathrm{M})$-mediated increased activity of the antioxidative system, proline content and maintains the membrane stability index [52]. Likewise, application of 24-epiBL mitigates $\mathrm{Ni}$ heavy metal stress in Brassica juncea by improving defense enzymes and proteins [54].

\subsection{Osmotic Stress}

Abiotic stresses such as drought and salinity stress freezing dehydration directly create osmotic pressures while chilling indirectly imposes osmotic stress. Plants showed different responses by altering various physiological and developmental processes when faced low temperature and dehydration condition. To overcome such harsh condition plants accumulate non-toxic osmoprotectants such as proline which is regulated by 1-pyrroline-5-carboxylate synthase (P5CS) and proline dehydrogenase (PDH). The expression of P5CS and $\mathrm{PDH}$ are down-regulated by an increased level of abscisic acid (ABA). The downregulation of effect P5CS is minimized by BL but fail to stimulate PDH. Homo-BL showed ameliorative effect drought tolerant (C306) and drought susceptible (HD2329) wheat exposed to various stress conditions. Exogenous application of homo-BL also had increased water content, nitrate reductase activity, photosynthesis and photosynthetic pigment and membrane stability under stress [55].

\subsection{Involvement of BRs in Modulation of Antioxidants Defense System Under Stress}

The generations of various ROS are usual in the regular aerobic metabolism in plants. Although stresses cause disturbance in ROS generation and their minimal scavenging ultimately lead to a physiological condition recognized as oxidative stress. Therefore, due to excessive oxidative stress, consequences include alteration of major biomolecules, nutrient imbalances, cell death, and retarded growth and development [56,48]. Plants developed many complex defense mechanisms to survive under outrageous unforgiving ecological conditions. Plant tolerance includes the incitement of multipart metabolic exercises incorporating legitimate adjust in antioxidative 
pathways and ROS-searching plans [57]. The defense system comprises the enzymatic and non-enzymatic components that are compulsory for osmotic alteration, maintenance of membranes, and ROS-scavenging [Figure 3] [56].

\section{CROSSTALK OF BRS WITH OTHER PHYTOHORMONE(S)}

BRs fulfill assorted capacities due to its association with various phytohormones, for example, abscisic corrosive, auxin, cytokinin, ethylene, gibberellin, jasmonic corrosive, polyamines (PA) and salicylic corrosive (SA), and to modify untold parts of plant development and formative procedures [58,59]. The disentangling of these unpredictable mechanisms of BR signaling and its relationship with molecular frameworks will be of articulated impact in enhancing present day agribusiness rehearses [Figure 4].

\subsection{BRs and ABA}

As well-known ABA inhibits seed germination and promotes seed dormancy during embryo maturation while antagonistically, BR stimulates seed germination [60]. However, detailed molecular mechanism needs extensive studies to recognize the whole mechanism of crosstalk [61]. Moreover, BR and ABA have been recommended to assume opposing parts in controlling seed germination and postgerminative development forms [62]. ABA hinders, while BRupgrades seed germination and post-germinative development forms. As of late, mutant examinations showed a synergistic relationship among $\mathrm{BR}$ and $\mathrm{ABA}$ in inciting reactions, for example, $\mathrm{H}_{2} \mathrm{O}_{2}$ creation, respiratory burst oxidase homolog 1 (RBOH1) quality articulation, NADPH oxidase action and in interceding heat and oxidative salt tolerance [63]. More advanced studies showed that ABA biosynthesis assumes a key part in supporting tolerance in BR-initiated pathways in plants.

\subsection{BRS and Auxins}

Crosstalk between BR and auxin regulates innumerable phases of plant growth and developmental routes [64-66]. Interactive effects of BRs and auxin involved physiological process such as hypocotyl elongation or root development. However, still, BR interaction with auxin in regulating stress responses has remained indefinable [67]. In Arabidopsis, the BR level required for development is interceded by BRAVIS RADIX (BRX) which is provoked by auxin showing that BRX demonstrations at the nexus of an input circle in Arabidopsis [68]. Surprisingly, the CPD gene and DWF4 gene required for BR biosynthesis are likewise controlled by BRX [23] showing a connection between BR biosynthesis and in auxin signaling [68]. In addition to dwarfism, the maize BR biosynthetic mutants have the presence of pistils in the tassel flowers and reduced tiller branch outgrowth [69]. Moreover, a connection among BR and auxin in plant development and improvement has been built up through cooperation among BIN2 and auxin reaction factors (ARF2). Recently, it was exhibited that the BR signaling part BIN2 can specifically collaborate with an auxin signaling segment ARF2, an individual from the auxin response factor group of transcriptional controllers [70]. Besides, rice genome secures seven YUCCA genes which encode the rate constraining catalysts for auxin biosynthesis [71] which are down-managed under drought stress. Furthermore, in yucca mutants, $40 \%$ higher transcript level in BR upregulation of genes has been reported [72] revealed the BR and auxin crosstalk point. Despite the fact that the relationship of BR and auxin has been all around archived basically in plant development

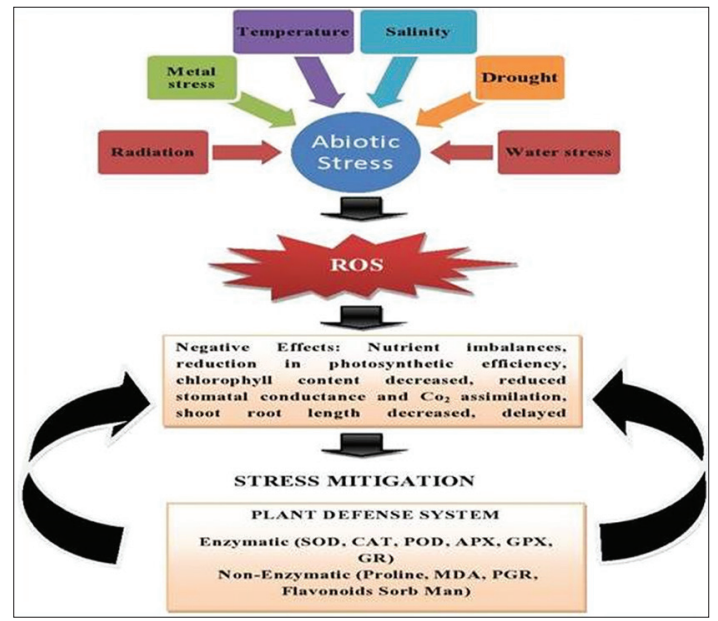

Figure 3: Interrelationship between abiotic stress reactive oxygen species generation and plant defense system

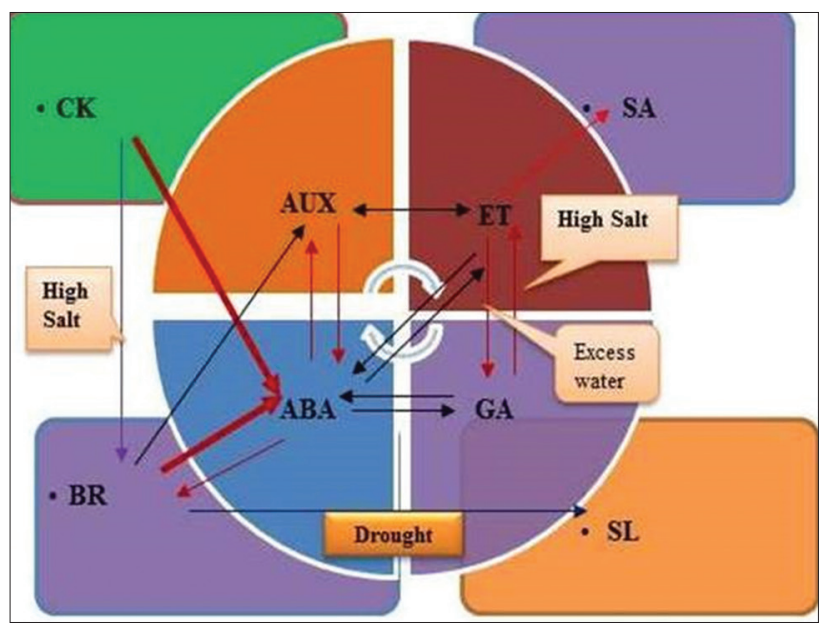

Figure 4: A generalized model of the hormones interaction under biotic and abiotic stress

and formative procedures, nonetheless, promote examinations are essential to comprehend the component of auxin and BR crosstalk associated with tolerance.

\subsection{BRs and Jasmonic Acid}

To enhance abiotic tolerance, synergistic connection of BR and JA assume key parts in the plant growth. It has likewise been shown that BR improves JA level in rice under stress [73], which unequivocally advances the declaration of thionin qualities encoding antimicrobial peptides demonstrating a potential crosstalk point with these two phytohormones. Strikingly, hindrance of JA incited accumulation of anthocyanins by brassinazole in Arabidopsis has been additionally detailed by BRs motioning on the JA pathway [74]. The transcript levels of JA biosynthesis quality and JA-initiated signaling gene were down-controlled when the BR focus was low. Be that as it may, on high BR focus, the transcript levels of JA biosynthesis and signaling gene were up-controlled. These results were, moreover, endorsed through exogenous foliar application with JA which incited the down-control of BR biosynthesis and signaling gene, OsDWF4 and OsBRI1 [27], showing counter communication among BR and $\mathrm{JA}$ in the rice roots. In addition, it has additionally been watched 
that BR biosynthesis controlled by improved JA-antecedent, 12-oxo-phytodienoic destructive, and subsequently joining BR and JA pathway initiation [27].

\subsection{BRs and Salicylic Acid}

Interaction between $\mathrm{BR}$ and SA revealed important role in alleviating biotic as well as abiotic stresses. Crosstalk of SA and BR conferred salt tolerance to plant with interaction of other stress hormones [75]. SA mediated gene NPR1, is an essential module of 24-epibrassinolidemediated increase in thermo- and salinity tolerance in Arabidopsis thaliana [75]. It is well known that SA has an ameliorative effect on salinity stress and other abiotic stresses [76]. In O. sativa, BR enhances tolerance to various biotic factors such as fungal and bacterial pathogen (Magnaporthe grisea and Xanthomonas oryzae).

\subsection{BRs and Polyamine}

Even though the significant progress made past decades, more exploration began to investigate the BR and PA crosstalk. Recent advancement showed that abiotic and biotic stresses facilitate elevation in free PA content by exogenous application of BR which helps to mitigate $\mathrm{Cu}$-oxidative stress [77,78]. Besides, BR treatment keeps up the ideal measure of spermidine fixation required for typical plant development and particularly enhanced the production of putrescine required for stress tolerance, however, diminishes the concentration of cadaverine which produces oxidative burst to balance substantial metal stress [79]. Further, the synergistic application of $\mathrm{Cu}$ and $\mathrm{BR}$ similarly decreases cadaverine redesigning SOD action required for resistance [80]. It shows the key part of BR-PA communication in giving abiotic stress resistance. In this manner, the utilization of this combination is essential for maintaining present day agribusiness and to unwind the qualities and translation factors associated with BR and PA signaling pathway.

\subsection{BRs and Nitric Oxide (NO)}

NO assumes indispensable parts in different plant physiological procedures, including plant development, advancement, and abiotic stresses $[81,82]$. A few lines of confirmation demonstrate that NO is associated with plant signal transduction due to water scarcity, press insufficiency, and ABA boost $[83,84]$. In this area, an exertion was made to explain the impacts of $\mathrm{NO}$ on $\mathrm{BR}$-actuated $\mathrm{ABA}$ aggregation in BR-prompted oxidative stress tolerances. Previous studies have demonstrated that water scarcity prompts NO production $[85,86]$, and NO improves the water stress resilience of plants. One of the conceivable components by which NO improves plant resilience to water stress is by the direction of ABA biosynthesis [87]. Be that as it may, it is not certain whether NO incites ABA biosynthesis in BR motioning submerged stress. The exogenous and endogenous level of BR expanded the age of NO in the mesophyll cells of maize leaves and the BR-incited ABA amassing was considerably decreased proposing that BR-initiated ABA gathering is reliant on BR-actuated NO generation. Taken together, our outcomes obviously propose that BRinstigated $\mathrm{NO}$ generation intercede $\mathrm{ABA}$ biosynthesis, which brings about the upgrade of resilience to the oxidative harm caused by water push. In addition, considers are important to uncover how NO controls BR-prompted ABA biosynthesis.

\section{CONCLUSION AND FUTURE PROSPECTS}

Environmental stresses well known are the mainly responsible for crop loss globally and become more critical day-by-day past few decades.
An environmental stress generates ROS which adversely affects metabolic and physiological process. Diverse strategies were applied to mitigate detrimental effect of stress on of which is the application of plant growth regulators has been deliberated as a better defensible alternative. In this continuation, BRs and linked compounds have been widely described to stabilize significances of several abiotic stresses including salt and heavy metals. Understanding the basic mechanism of BR homeostasis and dealing with its associations with different phytohormones will add new degree to BR investigate. Without lifting a finger of utilization and improvement of new approaches, it is evaluated that in future there will be a critical collection of data of BR activity and this could inevitably finish up in going with another age in plant formative and stress science.

\section{ACKNOWLEDGMENTS}

The authors are grateful to Dean, R\&D, Section, Integral University, Lucknow, for quick and crisp revision of manuscript and for allotting manuscript number (IU/R\&D/2017-MCN-0136).

\section{REFERENCES}

1. Parihar P, Singh S, Singh R, Singh VP, Prasad SM. Effect of salinity stress on plants and its tolerance strategies: A review. Environ Sci Pollut Res Int 2015;22:4056-75.

2. Kaur G, Kumar S, Nayyar H, Upadhyaya HD. Cold stress injury during the pod-filling phase in chickpea (Cicer arietinum L.): Effects on quantitative and qualitative components of seeds. J Agron Crop Sci 2008;194:457-64.

3. Mantri N, Patade V, Penna S, Ford R, Pang E. Abiotic stress responses in plants: Present and future. In: Abiotic Stress Responses in Plants. New York: Springer; 2012. p. 1-19.

4. Wang W, Vinocur B, Altman A. Plant responses to drought, salinity and extreme temperatures: Towards genetic engineering for stress tolerance. Planta 2003;218:1-4.

5. Khan NA, Nazar R, Iqbal N, Anjum NA, editors. Phytohormones and Abiotic Stress Tolerance in Plants. New York: Springer Science and Business Media; 2012. p. 15.

6. Asgher M, Khan MI, Anjum NA, Khan NA. Minimising toxicity of cadmium in plants-role of plant growth regulators. Protoplasma 2015;252:399-413.

7. Khatoon H, Ananya S, Ahmad F, Aisha K. Brassinosteroids - An essential steroidal regulator: Its structure, synthesis and signaling in plant growth and development - A review. Int J Curr Res Biosci Plant Biol 2017;4;88-96.

8. González-García MP, Vilarrasa-Blasi J, Zhiponova M, Divol F, Mora-García S, Russinova E, et al. Brassinosteroids control meristem size by promoting cell cycle progression in Arabidopsis roots. Development 2011;138:849-59.

9. Meudt WJ, Thompson MJ, Bennett HW. Investigations on the Mechanism of the Brassinosteroid Response. III. Techniques for Potential Enhancement of Crop Production [Barley, bean]. In Proceedings Annual Meeting Plant Growth Regulator Society of America; 1983.

10. Oh MH. Brassinosteroids accelerate the rate of cell division in isolated petal protoplasts of Petunia hybrida. J Plant Biotechnol 2003;5:63-7.

11. Zhiponova MK, Vanhoutte I, Boudolf V, Betti C, Dhondt S, Coppens $\mathrm{F}$, et al. Brassinosteroid production and signaling differentially control cell division and expansion in the leaf. New Phytol 2013;197:490-502.

12. Deng Z, Zhang X, Tang W, Oses-Prieto JA, Suzuki N, Gendron JM, et al. A proteomics study of brassinosteroid response in Arabidopsis. Mol Cell Proteomics 2007;6:2058-71. 
13. Vardhini BV, Rao SS. Effect of brassinosteroids on growth, metabolite content and yield of Arachis hypogaea. Phytochemistry 1998;48:927-30

14. Vardhini BV, Rao SS, Rao KV. Effect of brassinolide on growth, yield, metabolite content and enzyme activities of tomato (Lycopersicon esculentum) mill. In: Kumar A, Sudhir K, Sopory IK, editors. Recent Advances in Plant Biotechnology and its Applications. New Delhi, India: International Publishing House Ltd.; 2008. p. 133-9.

15. Zhang S, Hu J, Zhang Y, Xie XJ, Knapp A. Seed priming with brassinolide improves lucerne (Medicago sativa L.) seed germination and seedling growth in relation to physiological changes under salinity stress. Aust J Agric Res 2007;58:811-5.

16. Kartal G, Temel A, Arican E, Gozukirmizi N. Effects of brassinosteroids on barley root growth, antioxidant system and cell division. Plant Growth Regul 2009;58:261-7.

17. Shang Q, Song S, Zhang Z, Guo S. Exogenous brassinosteroid induced the salt resistance of cucumber (Cucumis sativus L.) seedlings. Zhongguo Nongye Kexue 2005;39:1872-7.

18. Hayat S, Hasan SA, Hayat Q, Ahmad A. Brassinosteroids protect Lycopersicon esculentum from cadmium toxicity applied as shotgun approach. Protoplasma 2010;239:3-14

19. Clouse SD, Sasse JM. Brassinosteroids: Essential regulators of plant growth and development. Annu Rev Plant Physiol Plant Mol Biol 1998;49:427-51.

20. Bajguz A. Metabolism of brassinosteroids in plants. Plant Physiol Biochem 2007;45:95-107.

21. Zhao B, Li J. Regulation of brassinosteroid biosynthesis and inactivation. J Integr Plant Biol 2012;54:746-59.

22. Zhabinskii VN, Khripach NB, Khripach VA. Steroid plant hormones: Effects outside plant kingdom. Steroids 2015;97:87-97.

23. Tanaka K, Asami T, Yoshida S, Nakamura Y, Matsuo T, Okamoto S, et al. Brassinosteroid homeostasis in Arabidopsis is ensured by feedback expressions of multiple genes involved in its metabolism. Plant Physiol 2005;138:1117-25.

24. Albrecht C, BoutrotF, Segonzac C, Schwessinger B, Gimenez-Ibanez S, Chinchilla $\mathrm{D}$, et al. Brassinosteroids inhibit pathogen-associated molecular pattern-triggered immune signaling independent of the receptor kinase BAK1. Proc Natl Acad Sci 2012;109:303-8.

25. Belkhadir Y, Jaillais Y, Epple P, Balsemão-Pires E, Dangl JL, Chory $\mathrm{J}$, et al. Brassinosteroids modulate the efficiency of plant immune responses to microbe-associated molecular patterns. Proc Natl Acad Sci U S A 2012;109:297-302.

26. De Vleesschauwer D, Van Buyten E, Satoh K, Balidion J, Mauleon R, Choi IR, et al. Brassinosteroids antagonize gibberellin- and salicylatemediated root immunity in rice. Plant Physiol 2012;158:1833-46.

27. Nahar K, Kyndt T, Hause B, Höfte M, Gheysen G. Brassinosteroids suppress rice defense against root-knot nematodes through antagonism with the jasmonate pathway. Mol Plant Microbe Interact 2013;26:106-15

28. Mitchell JW, Mandava N, Worley JF, Plimmer JR, Smith MV. Brassins - A new family of plant hormones from rape pollen. Nature 1970;225:1065-6.

29. Steffens GL. US Department of Agriculture Brassins Project: 1970-1980

30. Grove MD, Spencer GF, Rohwedder WK, Mandava N, Worley JF, Warthen JD, et al. Brassinolide, a plant growth-promoting steroid isolated from Brassica napus pollen. Nature 1979;281:216-7.

31. Cutler HG, Yokota T, Adam G, editors. Brassinosteroids: Chemistry, Bioactivity, and Applications. Washington, DC.: American Chemical Society; 1991.

32. Li J, Chory J. A putative leucine-rich repeat receptor kinase involved in brassinosteroid signal transduction. Cell 1997;90:929-38.

33. Wang GL, Xiong F, Que F, Xu ZS, Wang F, Xiong AS, et al. Morphological characteristics, anatomical structure, and gene expression: Novel insights into gibberellin biosynthesis and perception during carrot growth and development. Hortic Res $2015 ; 2: 15028$.

34. Wang GL, Xiong F, Que F, Xu ZS, Wang F, Xiong AS. Expression profiles of genes involved in jasmonic acid biosynthesis and signaling during growth and development of carrot. Acta Biochim Biophys Sin 2016;48;795-803.

35. Wu XJ, Wang GL, Song X, Xu ZS, Wang F, Xiong AS. Regulation of auxin accumulation and perception at different developmental stages in carrot. Plant Growth Regul 2016;80:243-51.

36. Taiz L, Zeiger E. Plant Physiology. USA: Sinaver Associates. Inc. Punlishers Sunderland, Massachusetts; 2002.

37. Fujioka S, Yokota T. Biosynthesis and metabolism of brassinosteroids. Annu Rev Plant Biol 2003;54:137-64.

38. Tang J, Han Z, Chai J. Q\&A: What are brassinosteroids and how do they act in plants? BMC Biol 2016;14:113.

39. Yokota T, Ogino Y, Suzuki H, Takahashi N, Saimoto H, Fujioka S, et al. Metabolism and biosynthesis of brassinosteroids. In: Cutler $\mathrm{H}$, Yokota T, Adam G, editors. Brassinosteroids Chemistry, Bioactivity, Applications. Washington, D.C.: American Chemical Society; 1991. p. 86-96.

40. Suzuki M, Xiang T, Ohyama K, Seki H, Saito K, Muranaka T, et al. Lanosterol synthase in dicotyledonous plants. Plant Cell Physiol 2006;47:565-71.

41. Mazorra LM, Holton N, Bishop GJ, Núñez M. Heat shock response in tomato brassinosteroid mutants indicates that thermo tolerance is independent of brassinosteroid homeostasis. Plant Physiol Biochem 2011;49:1420-8.

42. Aghdam MS, Mohammadkhani N. Enhancement of chilling stress tolerance of tomato fruit by postharvest brassinolide treatment. Food Bioprocess Technol 2014;7:909-14.

43. Janeczko A, Gullner G, Skoczowski A, Dubert F, Barna B. Effects of brassinosteroid infiltration prior to cold treatment on ion leakage and pigment contents in rape leaves. Biol Plant 2007;51:355-8.

44. Xi Z, Wang Z, Fang Y, Hu Z, Hu Y, Deng M, et al. Effects of 24-epibrassinolide on antioxidation defense and osmoregulation systems of young grapevines ( $V$. vinifera $\mathrm{L}$.) under chilling stress. Plant Growth Regul 2013;71:57-65.

45. Kumar M, Sirhindi G, Bhardwaj R, Kumar S, Jain G. Effect of exogenous $\mathrm{H}_{2} \mathrm{O}_{2}$ on antioxidant enzymes of Brassica juncea L. seedlings in relation to 24-epibrassinolide under chilling stress. Indian J Biochem Biophys 2010;47;378-82.

46. Singh AP, Savaldigoldstein S. Growth control: Brassinosteroid activity gets context. J Exp Bot 2015;66:1123-32.

47. Hasanuzzaman M, Hossain MA, da Silva JA, Fujita M. Plant response and tolerance to abiotic oxidative stress: Antioxidant defense is a key factor. In: Crop Stress and its Management: Perspectives and Strategies. Netherlands: Springer; 2012. p. 261-315.

48. Anjum NA, Umar S, Ahmad A. Oxidative Stress in Plants: Causes, Consequences and Tolerance. New Delhi: IK International Publishing House; 2012.

49. El-Khallal SM. The influence of some phyto-growth regulators on the activity of antioxidant system in maize plant under water stressed conditions. Bull Fac Sci Assiut Univ (Egypt) 2002;5:24-47.

50. Pitman MG, Läuchli A. Global impact of salinity and agricultural ecosystems. Salinity: Environment-Plants-Molecules. Vol. 3. Netherlands: Kluwer Academic; 2002. p. 20.

51. Munns R, Tester M. Mechanisms of salinity tolerance. Annu Rev Plant Biol 2008;59:651-81.

52. Rady MM. Effect of 24-epibrassinolide on growth, yield, antioxidant system and cadmium content of bean (Phaseolus vulgaris L.) plants under salinity and cadmium stress. Sci Hortic 2011;129:232-7.

53. Hayat S, Alyemeni MN, Hasan SA. Foliar spray of brassinosteroid enhances yield and quality of Solanum lycopersicum under cadmium 
stress. Saudi J Biol Sci 2012;19:325-35.

54. Kanwar MK, Bhardwaj R, Chowdhary SP, Arora P, Sharma P, Kumar S. Isolation and characterization of 24-epibrassinolide from Brassica juncea L. and its effects on growth, Ni ion uptake, antioxidant defense of Brassica plants and in vitro cytotoxicity. Acta Physiol Plant 2013;35:1351-62.

55. Sairam RK. Effects of homobrassinolide application on plant metabolism and grain yield under irrigated and moisturestress conditions of two wheat varieties. Plant Growth Regul 1994;14:173-81.

56. Gill SS, Tuteja N. Reactive oxygen species and antioxidant machinery in abiotic stress tolerance in crop plants. Plant Physiol Biochem 2010;48:909-30.

57. El-Mashad AA, Mohamed HI. Brassinolide alleviates salt stress and increases antioxidant activity of cowpea plants (Vigna sinensis). Protoplasma 2012;249:625-35.

58. Choudhary SP, Oral HV, Bhardwaj R, Yu JQ, Tran LS. Interaction of brassinosteroids and polyamines enhances copper stress tolerance in Raphanus sativus. J Exp Bot 2012;63:5659-75.

59. Gruszka D. The brassinosteroid signaling pathway - New key players and interconnections with other signaling networks crucial for plant development and stress tolerance. Int J Mol Sci 2013;14:8740-74.

60. Steber CM, McCourt P. A role for brassinosteroids in germination in Arabidopsis. Plant Physiol 2001;125:763-9.

61. Zhang S, Cai Z, Wang X. The primary signaling outputs of brassinosteroids are regulated by abscisic acid signaling. Proc Natl Acad Sci 2009;106:4543-8.

62. $\mathrm{Hu} \mathrm{Y,} \mathrm{Yu} \mathrm{D.} \mathrm{Brassinosteroid} \mathrm{insensitive} 2$ interacts with abscisic acid insensitive 5 to mediate the antagonism of brassinosteroids to abscisic acid during seed germination in Arabidopsis. Plant Cell 2014;26:4394-408.

63. Zhou J, Wang J, Li X, Xia XJ, Zhou YH, Shi K, et al. $\mathrm{H}_{2} \mathrm{O}_{2}$ mediates the crosstalk of brassinosteroid and abscisic acid in tomato responses to heat and oxidative stresses. J Exp Bot 2014;65:4371-83.

64. Hao J, Yin Y, Fei SZ. Brassinosteroid signaling network: Implications on yield and stress tolerance. Plant Cell Rep 2013;32:1017-30.

65. Saini S, Sharma I, Kaur N, Pati PK. Auxin: A master regulator in plant root development. Plant Cell Rep 2013;32:741-57.

66. Chaiwanon J, Wang ZY. Spatiotemporal brassinosteroid signaling and antagonism with auxin pattern stem cell dynamics in Arabidopsis roots. Curr Biol 2015;25:1031-42.

67. Kissoudis C, van de Wiel C, Visser RG, van der Linden G. Enhancing crop resilience to combined abiotic and biotic stress through the dissection of physiological and molecular crosstalk. Front Plant Sci 2014;5.

68. Mouchel CF, Osmont KS, Hardtke CS. BRX mediates feedback between brassinosteroid levels and auxin signalling in root growth. Nature 2006;443:458.

69. Best NB, Hartwig T, Budka J, Fujioka S, Johal G, Schulz B, et al. nana plant 2 encodes a maize ortholog of the Arabidopsis brassinosteroid biosynthesis gene dwarf1, identifying developmental interactions between brassinosteroids and gibberellins. Plant Physiol 2016;171:2633-47.

70. Vert G, Walcher CL, Chory J, Nemhauser JL. Integration of auxin and brassinosteroid pathways by Auxin response factor 2. Proc Natl Acad Sci 2008;105:9829-34.

71. Yamamoto Y, Kamiya N, Morinaka Y, Matsuoka M, Sazuka T. Auxin biosynthesis by the YUCCA genes in rice. Plant Physiol 2007;143:1362-71.
72. Nemhauser JL, Mockler TC, Chory J. Interdependency of brassinosteroid and auxin signaling in Arabidopsis. PLoS Biol 2004;2:e258.

73. Kitanaga Y, Jian C, Hasegawa M, Yazaki J, Kishimoto N, Kikuchi S, et al. Sequential regulation of gibberellin, brassinosteroid, and jasmonic acid biosynthesis occurs in rice coleoptiles to control the transcript levels of anti-microbial thionin genes. Biosci Biotechnol Biochem 2006;70:2410-9.

74. Peng Z, Han C, Yuan L, Zhang K, Huang H, Ren C. Brassinosteroid enhances jasmonate-induced anthocyanin accumulation in Arabidopsis seedlings. J Integr Plant Biol 2011;53:632-40.

75. Divi UK, Rahman T, Krishna P. Brassinosteroid-mediated stress tolerance in Arabidopsis shows interactions with abscisic acid, ethylene and salicylic acid pathways. BMC Plant Biol 2010;10:151.

76. Ahmad F, Singh A, Kamal A. Ameliorative effect of salicylic acid in salinity stressed Pisum sativum by improving growth parameters, activating photosynthesis and enhancing antioxidant defense system. Biosci Biotech Res Comm 2017;10:481-9.

77. Liu JH, Moriguchi T. Changes in free polyamine titers and expression of polyamine biosynthetic genes during growth of peach in vitro callus. Plant Cell Rep 2007;26:125-31.

78. Choudhary SP, Bhardwaj R, Gupta BD, Dutt P, Gupta RK, Biondi S, et al. Epibrassinolide induces changes in indole-3-acetic acid, abscisic acid and polyamine concentrations and enhances antioxidant potential of radish seedlings under copper stress. Physiol Plant 2010;140:280-96.

79. Takahashi T, Kakehi JI. Polyamines: Ubiquitous polycations with unique roles in growth and stress responses. Anna Bot 2009;105:1-6.

80. Kuznetsov VV, Stetsenko LA, Shevyakova NI. Exogenous cadaverine induces oxidative burst and reduces cadaverine conjugate content in the common ice plant. J Plant Physiol 2009;166:40-51.

81. Zheng C, Jiang D, Liu F, Dai T, Liu W, Jing Q, et al. Exogenous nitric oxide improves seed germination in wheat against mitochondrial oxidative damage induced by high salinity. Environ Exp Bot 2009;67:222-7.

82. Zafra A, Rodríguez-García MI, de Dios Alché J. Cellular localization of ROS and $\mathrm{NO}$ in olive reproductive tissues during flower development. BMC Plant Biol 2010;10:36.

83. Sun B, Jing Y, Chen K, Song L, Chen F, Zhang L. Protective effect of nitric oxide on iron deficiency-induced oxidative stress in maize (Zea mays). J Plant Physiol 2007;164:536-43.

84. Farooq M, Wahid A, Basra SM. Improving water relations and gas exchange with brassinosteroids in rice under drought stress. J Agron Crop Sci 2009;195:262-9.

85. Gould KS, Lamotte O, Klinguer A, Pugin A, Wendehenne D. Nitric oxide production in tobacco leaf cells: A generalized stress response? Plant Cell Environ 2003;26:1851-62.

86. Neill SJ, Desikan R, Hancock JT. Nitric oxide signalling in plants. New Phytol 2003;159:11-35.

87. Xing H, Tan L, An L, Zhao Z, Wang S, Zhang C. Evidence for the involvement of nitric oxide and reactive oxygen species in osmotic stress tolerance of wheat seedlings: Inverse correlation between leaf abscisic acid accumulation and leaf water loss. Plant Growth Regul 2004;42:61-8.

\footnotetext{
How to cite this article:

Ahmad F, Singh A, Kamal A. Crosstalk of brassinosteroids with other phytohormones under various abiotic stresses. J App Biol Biotech. 2018;6(1):56-62. DOI: 10.7324/JABB.2018.60110
} 